\title{
Boehmite and Akaganeite 1D and 2D Mesostructures: Synthesis, Growth Mechanism, Ageing Characteristics and Surface Nanoscale Roughness Effect on Water Purification
}

\author{
Leonid A. Kaledin (D), Fred Tepper, Yuly Vesga, and Tatiana G. Kaledin \\ Argonide Corporation, Nanomaterial \& Filtration Technologies, 291 Power Court, Sanford, Florida 32771, USA \\ Correspondence should be addressed to Leonid A. Kaledin; kaledin@argonide.com
}

Received 23 July 2019; Accepted 21 September 2019; Published 6 November 2019

Guest Editor: Pietro Calandra

Copyright (c) 2019 Leonid A. Kaledin et al. This is an open access article distributed under the Creative Commons Attribution License, which permits unrestricted use, distribution, and reproduction in any medium, provided the original work is properly cited.

\begin{abstract}
The role of surface nanoscale roughness on the charging behavior of nanostructured $\gamma$-AlOOH (Boehmite) and $\beta$-FeOOH (Akaganeite) $/ \gamma$-AlOOH (Boehmite) mesostructures deposited onto siliceous substrates has been investigated. Two-dimensional (2D) quantum-sized and one-dimensional (1D) nanometer size $\gamma$-AlOOH (Boehmite) structures and 2D atomically-thin $\beta$ $\mathrm{FeOOH}$ (Akaganeite) nanobelts with a mean width of approximately $10 \mathrm{~nm}$ were deposited onto siliceous substrates in aqueous processes at moderate temperatures. Low cost and large scale manufacturing of siliceous substrates coated with $2 \mathrm{D}$ and $1 \mathrm{D} \gamma$ AlOOH (Boehmite) crystallites of $2.7 \pm 0.5 \mathrm{~nm}$ in diameter, with an average length of $2.9 \pm 0.9 \mathrm{~nm}$ and $250 \pm 50 \mathrm{~nm}$, respectively, that were further functionalized with atomically thin $2 \mathrm{D} \beta$-FeOOH (Akaganeite) nanobelts was demonstrated. Zeta potentials of surfaces have been characterized by direct measurement of streaming potentials in $\mathrm{NaCl}$ aqueous electrolyte. A model explaining the $\mathrm{pH}$ dependent behavior of the zeta potential was proposed. The isoelectric point values of rough nanostructured surfaces are three $\mathrm{pH}$ units higher as compare to the flat crystalline $\gamma$-AlOOH (Boehmite) and $\beta$-FeOOH (Akaganeite) surfaces, resulting in a high removal efficacy of submicron particles from aqueous suspension by the surfaces with combined microscale and nanoscale structures. This suggests the existence of a coupling electrokinetic effect of the local electrical double layer (EDL) fields with the local flow fields.
\end{abstract}

\section{Introduction}

Coating sand and diatomaceous earth (DE) particles with aluminum and ferrous hydroxides changes the zeta potential of filtration media from negative to positive in the $\mathrm{pH}$ range from 3 to 11 and from 3 to 10, respectively. As a result, those surface modified media greatly improve removal efficacy of submicron particles [1-8]. The role of the electrical double layer (EDL) and van der Waals (VDW) forces in particle deposition is often viewed in terms of Derjaguin-LandauVerwey-Overbeek (DLVO) theory $[9,10]$, which was developed for smooth, homogeneous particles with ideal geometries and with no EDL overlap. The influence of surface roughness of filter media on streaming potential measurements is well documented [11]. The samples made from the same material with different surface roughness, measured by the same method, in the same device showed zeta potential values significantly different from each other, while the isoelectric point (IEP) values were identical between the measurements [11]. Moreover, the velocity profiles for two different spots along the surface of a multifilament fabric showed circulation pattern between two yarns during the streaming potential measurement. The general impact of roughness is to amplify the long-range behavior of noncontact DLVO forces with the approximate amplification factor of exponential force between rough and smooth surfaces $\exp \left(\sigma_{\text {roughness }}{ }^{2} / \lambda_{\text {Debye }}{ }^{2}\right)$, where $\sigma_{\text {roughness }}$ is the mean roughness [12]. Furthermore, the influence of particle shape and particle size on the zeta potential of colloidal suspensions is well known for the case of ultrapure silica powders where the authors found that the maximum zeta potential occurs for particle size ranging between $0.1 \mu \mathrm{m}$ and $1 \mu \mathrm{m}$ [13]. 
A variety of analytical and numerical models have been developed to describe the pressure-driven flow over heterogeneous surfaces. The vast majority of these models assume that the local electric double layer (EDL) field is independent of the flow field [14-17]. However, for pressure-driven flow over a surface with heterogeneous patches, the local EDL fields are not uniform. This means that they are more different above a patch than in the region between the patches. This irregularity produces distortions in the equilibrium electrostatic field. Consequently, the electrostatic potential can alter the value of the zeta potential from its expected value over a surface with uniformly smeared surface under conditions of moderate surface charge [18-21]. The characteristic symptom of field distortion is the generation of flow velocities in all three coordinate directions, including a circulation pattern perpendicular to the main flow axis.

The present study of $1 \mathrm{D}$ and $2 \mathrm{D}$ nanostructures was motivated by three primary considerations. The first one was to present the characterization of the surface's zeta potentials by direct measurement of streaming potentials in $\mathrm{NaCl}$ aqueous electrolyte. The isoelectric point values of rough nanostructured surfaces are three $\mathrm{pH}$ units higher as compare to the flat crystalline $\gamma$ - $\mathrm{AlOOH}$ and $\beta$-FeOOH surfaces, resulting in a high removal efficacy for different classes of contaminants such as metal ions [2], small colloidal particles [6-8], as well as biological particles like virus, bacteria and cyst $[1,2]$. The second motivation was to develop a model that explains the $\mathrm{pH}$ dependent behavior of the zeta potential based on contributions from the three morphological planes of different chemical composition existing at siliceous particles coated with $2 \mathrm{D}$ and $1 \mathrm{D} \gamma$-AlOOH crystallites: $\gamma$-AlOOH face and edge layers, and silica basal layer which are complex oxides of the two constituents: $\gamma$-AlOOH and $\mathrm{SiO}_{2}$. The third one was provided by ageing characteristics of the 2D, $1 \mathrm{D} \gamma-\mathrm{AlOOH}$ and $2 \mathrm{D} \beta-\mathrm{FeOOH} /$ $2 \mathrm{D} \gamma$-AlOOH crystallites, which showed no degradation in performance (i.e., TEM, particle size distribution, etc.) over periods of more than seven (2D materials) and fourteen (1D materials) years. This is a very important finding since siliceous substrates coated with 1D arrays is manufactured and sold as non-woven media by Ahlstrom Filtration LLC under the tradename Disruptor ${ }^{\mathrm{TM}}$. Siliceous substrates coated with the $2 \mathrm{D} \gamma-\mathrm{AlOOH}$ and with a combination of $2 \mathrm{D} \gamma$ $\mathrm{AlOOH}$ and $2 \mathrm{D} \beta$-FeOOH crystallites is manufactured by Argonide Corporation in large scale multi-tonnage processes.

\section{Materials and Methods}

2.1. Transmission Electron Microscopy (TEM) Study. The TEM images (Figure 1(a), 1(b)) were recorded on the JEOL JEM2010 TEM at $200 \mathrm{kV}$ accelerating voltage. The high resolution TEM (HRTEM) images (Figure 1(c)-1(f)) were recorded on the Tecnai $\mathrm{F} 30$ at $300 \mathrm{kV}$ accelerating voltage. It is important to note that boehmite bulk $\gamma$-AlOOH material has melting temperature over $1000^{\circ} \mathrm{C}\left(\mathrm{T}_{\text {melt }} 2050^{\circ} \mathrm{C}\right.$ after several phase transformations, i.e., $\gamma-\rightarrow, \delta-\rightarrow, \theta-\rightarrow$ and $\alpha-)$ [22]. It is also chemically inert and exhibits no decomposed surface layer in air, giving it the best chances of having $2 \mathrm{D}$ counterparts stable at room temperature [23].
Furthermore, it appears that the TEM high energy electrons needed to get enough resolution do not cause apparent damage to the sample.

2.2. Synthesis of $1 D \gamma$-AlOOH Crystals. The synthesis of one-dimensional (1D) $2.7 \pm 0.5$ nanometer diameter $250 \pm$ $50 \mathrm{~nm}$ long $\gamma$-AlOOH nanofibers seen in Figure 1(a) was accomplished via reaction of aluminum powder with alkaline water: [6].

$$
2 \mathrm{Al}(\mathrm{s})+4 \mathrm{H}_{2} \mathrm{O}(\mathrm{l}) \rightarrow 2 \mathrm{AlOOH}(\mathrm{s})+3 \mathrm{H}_{2}(\mathrm{~g})
$$

The synthesis of one-dimensional (1D) nanometer-sized $\gamma$-AlOOH atomic crystals adhered to siliceous and cellulosic substrates was accomplished via reaction (1) where aluminum powder reacts with alkaline water [6]. Amounts of $0.5 \mathrm{~g}$ of aluminum metal powder and $1.5 \mathrm{~g}$ of amorphous borosilicate glass microfiber with average diameter of $0.6 \mu \mathrm{m}$ were dispersed in $0.5 \mathrm{~L}$ liter of $\mathrm{RO}$ water and were reacted in a $1 \mathrm{~L}$ stainless steel pot in the presence of $1 \mathrm{~mL}$ of $10 \mathrm{M} \mathrm{NaOH}$ at ambient pressure. The suspension was heated to its boiling point at ambient pressure while mixing with an air-driven mixer equipped with $5 \mathrm{~cm}$ diameter impeller at 300 RPM. The suspension was cooled down to $40-50^{\circ} \mathrm{C}$, neutralized with $10 \%$ sulfuric acid to $\mathrm{pH} 6-8$. The non-woven paper-like mat were formed by conventional wet-laid paper making technology. Nitrogen BET (Brunauer, Emmett, Teller) specific surface area of dry sample of $1 \mathrm{D} \gamma$-AlOOH nanostructure (Figure 1(a)) was $S_{B E T}^{\gamma-\mathrm{AlOOH}}=475 \mathrm{~m} 2 / \mathrm{g} \mathrm{[6]}$.

2.3. Synthesis of $2 \mathrm{D}$ Quantum-Sized $\gamma$-AlOOH Crystals Adhered to Siliceous Substrates. Synthesis of 2D quantumsized $\gamma$-AlOOH crystals adhered to siliceous substrates was accomplished via the same reaction (equation (1)) of aluminum powder in the presence of siliceous substrate with alkaline water. The step-by step descriptions of the 2D quantum-sized $\gamma$-AlOOH crystals synthesis adhered to siliceous substrate are reported in Ref. [8] The siliceous powder, in form of diatomaceous earth (DE) was dispersed in 4 liters of RO water and allowed to react with $17.5 \mathrm{~g}$ of micron size aluminum powders in the presence of $40 \mathrm{~mL}$ of $10 \mathrm{M} \mathrm{NaOH}$ at ambient pressure. It was heated to boiling point while mixing with an air-driven mixer at 300 RPM. Then, the suspension was cooled down to $40-50^{\circ} \mathrm{C}$ and neutralized to $\mathrm{pH}$ 6-8 with $10 \%$ sulfuric acid. Decantation was allowed. Then, it was dried overnight at $100^{\circ} \mathrm{C}$. Finally, the media was crushed and sieved through a 170-mesh sieve. Nitrogen BET specific surface area of dry sample of $5 \mu \mathrm{m}$ diameter diatomaceous earth (DE) particles coated with quantum-sized 2D $\gamma$-AlOOH crystals of $2.7 \pm 0.5 \mathrm{~nm}$ in diameter and $2.9 \pm 0.9 \mathrm{~nm}$ long (Figure 1(c), 1(d)) increased from $S_{B E T}^{D E, A P S=5 \mu m}=51 \mathrm{~m}^{2} / \mathrm{g}$ to $S_{B E T}^{\gamma-\mathrm{AlOOH} / D E}=69 \mathrm{~m}^{2} / \mathrm{g}$. This suggests formation of additional surfaces on the substrate as seen in Figures 1(c), 1(d) and in a sketch of Figure 2(a).

2.4. Synthesis of $1 D$ Nanometer-Sized $\gamma$-AlOOH Crystals Adhered to Siliceous Substrate. The synthesis of $1 \mathrm{D} 2.7$ \pm 0.5 nanometer diameter $\gamma$-AlOOH nanofibers seen in Figure 1(a) adhered to siliceous substrate (Figure 1(b)) 


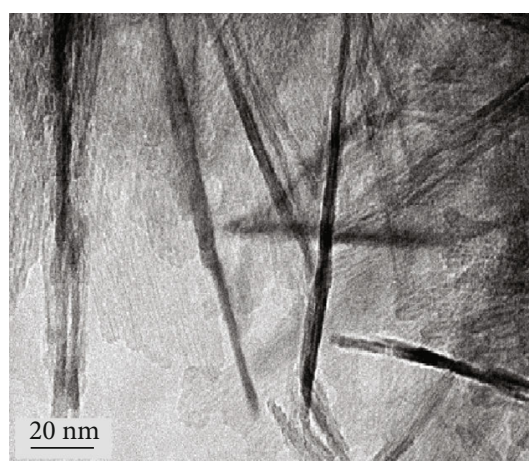

(a)

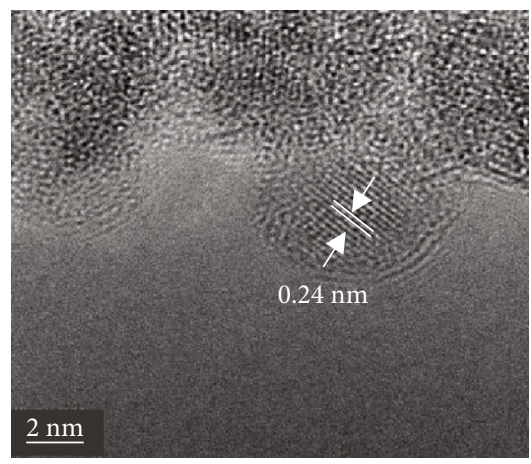

(c)

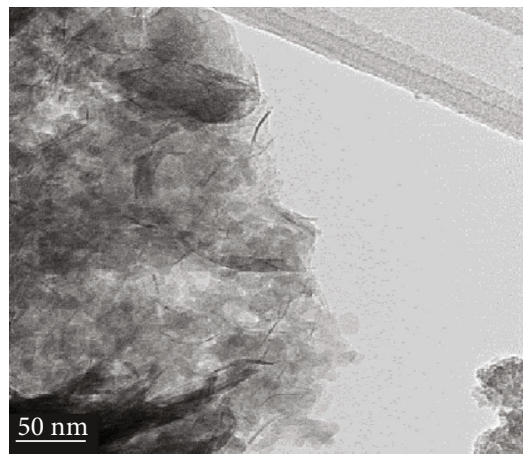

(e)

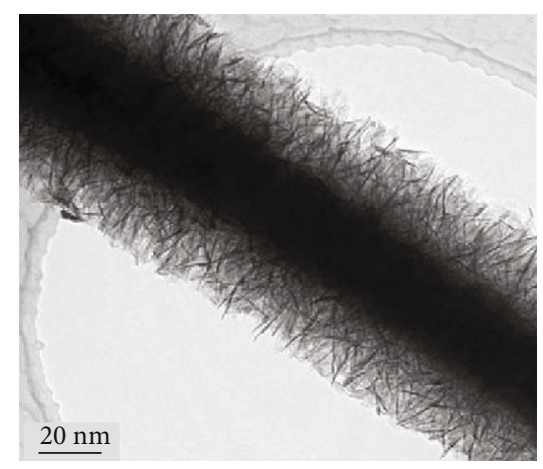

(b)

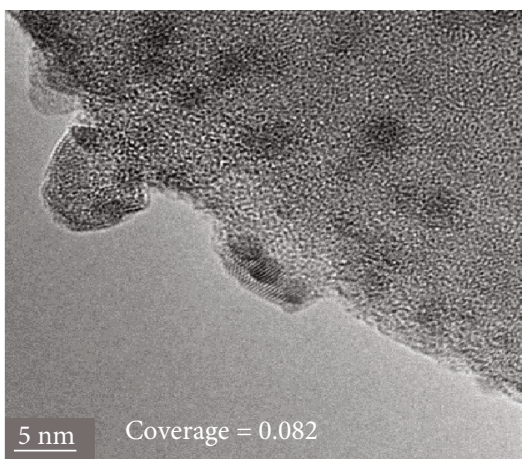

(d)

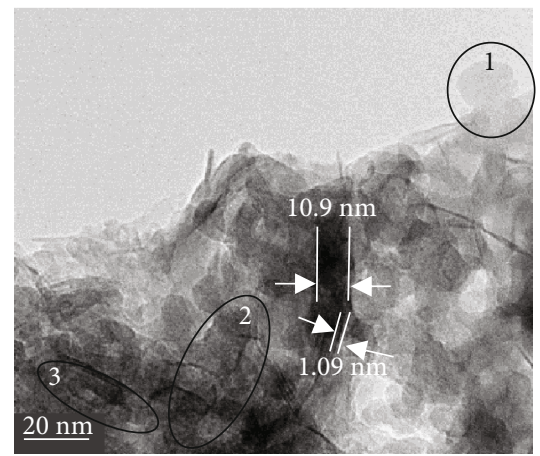

(f)

FIgURE 1: TEM characterization of 2D and $1 \mathrm{D} \gamma-\mathrm{AlOOH}$ and $2 \mathrm{D} \beta-\mathrm{FeOOH}$ crystallites: (a) TEM image of the 1D $\gamma$-AlOOH crystallites [6]; (b) TEM image of the $1 \mathrm{D} \gamma$-AlOOH crystallites attached to a $0.6 \mu \mathrm{m}$ diameter microglass fiber [6]; (c) HRTEM image of the edge coverage of $5 \mu \mathrm{m}$ diameter $\mathrm{DE}$ particle by the $2 \mathrm{D} \gamma-\mathrm{AlOOH}$ crystallites with atomic resolution. The separation of $\approx 0.24 \mathrm{~nm}$ is in agreement with the bulk boehmite lattice parameter $d_{(020)}=0.242(4) \mathrm{nm}$ [24]; (d) HRTEM image of the surface coverage of $5 \mu \mathrm{m}$ diameter DE particle by the 2D $\gamma$ $\mathrm{AlOOH}$ crystallites; (e), (f) HRTEM images of the surface coverage of $5 \mu \mathrm{m}$ diameter DE particle by $2 \mathrm{D}$. $\gamma$-AlOOH crystallites further functionalized with $2 \mathrm{D}$ atomically thin nanobelts of akaganeite $\beta$-FeOOH crystallites.

was accomplished via the same reaction (equation (1)) of aluminum powder with alkaline water in the presence of the substrate [6]. The non-woven paper-like mat was formed by conventional wet-laid paper making technology.

2.5. Synthesis of Atomically Thin $2 \mathrm{D} \beta-\mathrm{FeOOH}$ Nanobelt Crystals Adhered to Siliceous Substrates Preliminary Coated with 2D Quantum-Sized $\gamma$-AlOOH Crystals. The step-by step description of the $2 \mathrm{D}$ quantum-sized $\beta$-FeOOH crystals synthesis adhered to siliceous substrate were initially reported in Ref. [8] The BET (Brunauer, Emmett, Teller) value due to addition of ferric chloride increased by $42 \%$ from $S_{B E T}^{\gamma-\mathrm{AlOOH} / D E}=69 \mathrm{~m} 2 / \mathrm{g} \quad$ to $S_{B E T}^{\gamma-\mathrm{AlOOH} / \beta-\mathrm{FeOOH} / D E}=98 \mathrm{~m} 2 / \mathrm{g}$.
This suggests formation of additional surfaces on the substrate as seen in Figure 1(f) (insets 1-3) and in a sketch of Figure 2(b) of atomically thin nanobelts oriented parallel and normal to the substrate (insets 1 and 3) and under an angle (inset 2) with electron beam either perpendicular (inset 1), parallel (inset 3), or under angle (inset 2) to the nanobelt.

\section{Results and Discussion}

3.1. High Resolution TEM Analysis. Representative samples of $2 \mathrm{D}$ and $1 \mathrm{D}$ materials obtained by the procedures described above were investigated further by HRTEM. Figures 1(c), 


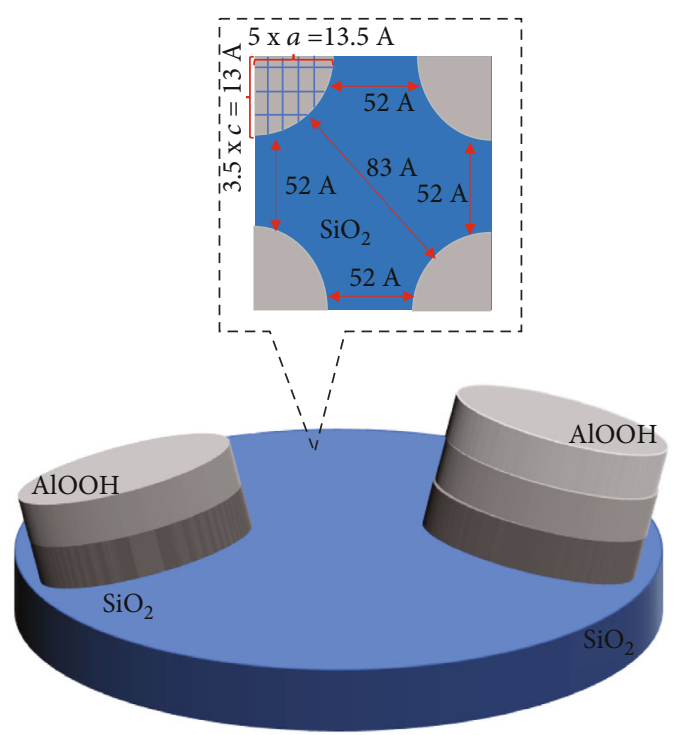

(a)

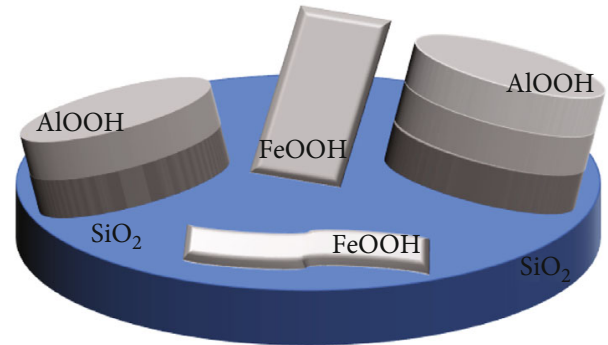

(b)

Figure 2: Sketches of $2 \mathrm{D} \gamma-\mathrm{AlOOH}$ and $2 \mathrm{D} \beta-\mathrm{FeOOH}$ crystallites deposited onto siliceous substrate: (a) The lateral dimensions (diameter) are 7-10 times of the $\gamma$-AlOOH $a-c$ unit cell dimensions; (b) The 2D $\gamma$-AlOOH/DE surface functionalized with $2 \mathrm{D}$ atomically thin nanobelts of $2 \mathrm{D} \beta$-FeOOH crystallites.

1(d) show examples of the atomic-resolution HRTEM images of $2 \mathrm{D} \gamma$-AlOOH crystallites. Thickness of the $2 \mathrm{D} \gamma-\mathrm{AlOOH}$ crystallites was estimated to be $2.9 \pm 0.9 \mathrm{~nm}$ based on the HRTEM images (Figures 1(c), 1(d)). When the lateral dimensions of $2 \mathrm{D} \gamma$-AlOOH structure are approximated by a circle, they are 7 and 10 times greater than the boehmite $a$ and $c$ unit cell dimensions, correspondently (Figure 2, insert). This is consistent with boehmite crystal growth, which occurs mainly along the $a-c$ plane where atomic inplane bonds are stronger than the weak, van der Waals (VDW)-type, interlayer bond along the $b$-axis [24]. Assuming that the crystals seen in Figures 1(c), 1(d) are fully dense $\gamma$-AlOOH cylinders (Figure 2(a)) with diameter $d=2.7 \pm$ $0.5 \mathrm{~nm}$ that covers a fraction $\theta=0.082 \pm 0.016$ of the silica surface (Figure 1(d)) with nitrogen BET (Brunauer, Emmett, Teller) specific surface area values of $S_{B E T}^{D E, A P S=5 \mu m}=51 \mathrm{~m} 2 / \mathrm{g}$ and $S_{B E T}^{\gamma-\mathrm{AlOOH} / D E}=69 \mathrm{~m} 2 / \mathrm{g}$, the ratio

$$
l / d=\left(S_{B E T}^{\gamma-\mathrm{AlOOH} / D E}-S_{B E T}^{D E}\right) /\left(4 S_{B E T}^{D E} \theta\right) \approx 1.08 \pm 0.20
$$

translates into $l=2.9 \pm 0.9 \mathrm{~nm}$ implying that the average length $l$ of the $2 \mathrm{D} \gamma$-AlOOH crystals seen in Figures 1(c), $1(\mathrm{~d})$ is 2-3 times of boehmite cell dimension $b=1.212(1)$ $\mathrm{nm}$ [24]. Figure 2(a) shows a sketch of $2 \mathrm{D} \gamma-\mathrm{AlOOH}$ crystallites comprising from two or three atomically thin layers deposited onto siliceous substrate linked together by the weak van der Waals (VDW)-type interlayer bond along the $b$-axis.

The width of $2 \mathrm{D}$ nanobelt $\beta$-FeOOH crystals attached to silica surface is 9-10 times of the akaganeite $a$ or $c$ unit cell dimension (see Figures 1(e), 1(f) between white arrows). This is consistent with akaganeite crystal growth, which occurs mainly along the $a-c$ plane in both directions where atomic in-plane bonds are stronger than the weak van der Waals (VDW)-type interlayer bonds along the $b$-axis.

Such lateral 2D structures on silica surface would not increase available BET (Brunauer, Emmett, Teller) surface area. Yet, the BET surface area increased by $42 \%$ from $S_{B E T}^{\gamma-\mathrm{AlOOH} / D E}=69 \mathrm{~m}^{2} / \mathrm{g}$ to $S_{B E T}^{\beta-\mathrm{FeOOH} / \gamma-\mathrm{AlOOH} / D E}=98 \mathrm{~m}^{2} / \mathrm{g}$. This suggests the formation of additional surfaces on siliceous substrate as seen in Figure 1(f) (insets 1-3). Single-, doubleor few-layer crystallites could be identified in an optical and TEM microscopes due to their different contrast that increases with increasing number of layers [25]. Further, assuming that these atomically thin nanobelts are fully dense $\beta$-FeOOH parallelepipeds that covers a fraction of silica surface of $\theta=0.03 \pm 0.02$ (Figures $1(\mathrm{e}), 1(\mathrm{f})$ ), the BET specific surface area value would increase by:

$$
\begin{aligned}
\Delta S & =\left(S_{B E T}^{\beta-\mathrm{FeOOH} / \gamma-\mathrm{AlOOH} / D E}-S_{B E T}^{\gamma-\mathrm{AlOOH} / D E}\right) \\
& =2 \theta / \delta \rho_{\mathrm{FeOOH}} \approx 20 \pm 15 \mathrm{~m}^{2} / \mathrm{g}
\end{aligned}
$$

where $\delta$ is the thickness of 2D platelets approximately equals to $a$ or $c$ akaganeite cell dimensions of $1 \mathrm{~nm}$. Such a model explains a $42 \%$ increase in BET surface area from $S_{B E T}^{\gamma-\mathrm{AlOOH} / D E}=69 \mathrm{~m}^{2} / \mathrm{g}$ to $S_{B E T}^{\beta-\mathrm{FeOOH} / \gamma-\mathrm{AlOOH} / D E}=98 \mathrm{~m} 2 / \mathrm{g}$.

3.2. Zeta Potentials of $2 \mathrm{D}$ and $1 \mathrm{D} \gamma$-AlOOH and $2 \mathrm{D} \gamma$ AlOOH/ $\beta-\mathrm{FeOOH}$ Crystallites Deposited onto Siliceous Particles. It was found that siliceous particles coated with 2D and 1D $\gamma$-AlOOH crystallites are positively charged in aqueous solution with zeta potential $\geq 40 \mathrm{mV}$ [26] at $\gamma$ $\mathrm{AlOOH}$ loading greater than 15 weight percent (wt\%) [1] as compared to the negatively charged character of the bare 


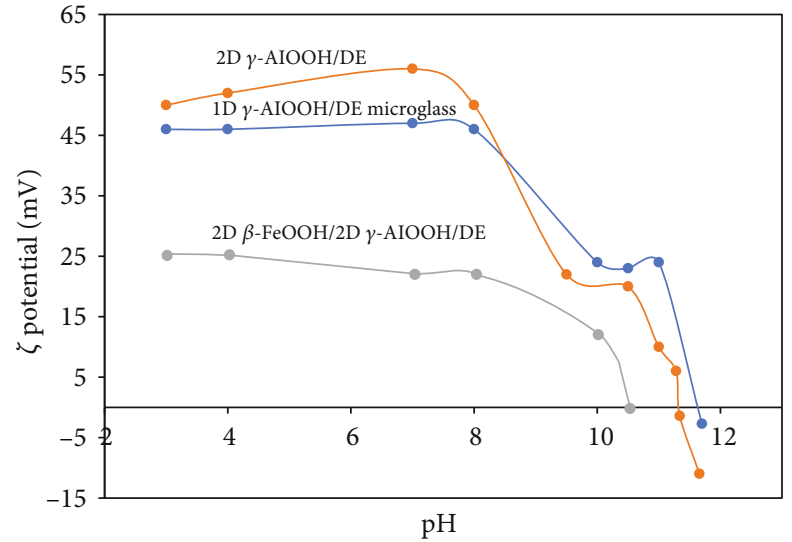

(a)

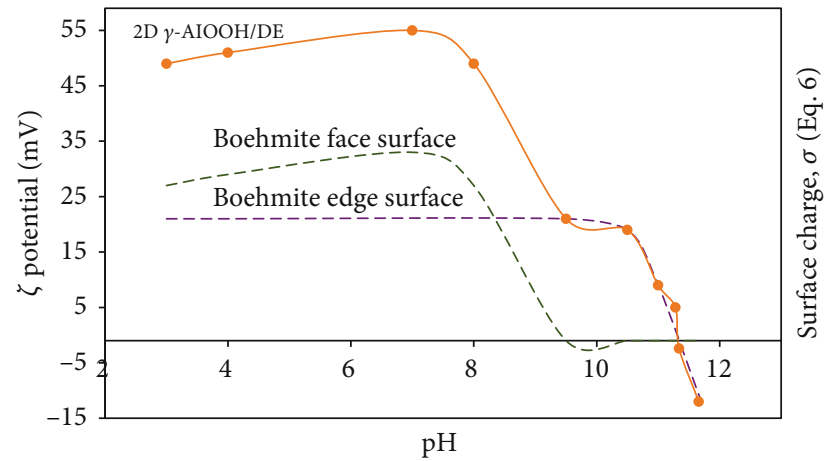

(b)

FIGURE 3: True zeta potentials of siliceous powder coated with 1D, $2 \mathrm{D} \gamma$-AlOOH and $2 \mathrm{D} \beta-\mathrm{FeOOH} / 2 \mathrm{D} \gamma-\mathrm{AlOOH}$ crystallites as a function of $\mathrm{pH}$ : (a) Siliceous powder coated with 1D, 2D $\gamma$ $\mathrm{AlOOH}[26]$ and $2 \mathrm{D} \beta$-FeOOH$/ 2 \mathrm{D} \gamma$-AlOOH crystallites (present work). (b) Surface protonation of two distinct types of $\mathrm{OH}$ groups localized at the boehmite face and edge surfaces.

siliceous substrates (zeta potential $\leq-70 \mathrm{mV}$ ) [1]. Figure 3 shows zeta potential of siliceous powder coated with $2 \mathrm{D}$ and $1 \mathrm{D} \gamma$-AlOOH and with $2 \mathrm{D} \beta$-FeOOH/2D $\gamma$-AlOOH crystallites as a function of $\mathrm{pH}$. The point of zero charge $\left(\mathrm{pH}_{\mathrm{PZC}}\right)$ describes the condition when the electrical charge density on a surface is zero [27]. The $\mathrm{pH}_{\mathrm{PZC}}$ values of siliceous particles coated with 1D, 2D $\gamma-\mathrm{AlOOH}$, and 2D $\beta$ $\mathrm{FeOOH} / 2 \mathrm{D} \gamma-\mathrm{AlOOH}$ were determined to be $11.6 \pm 0.2$ for $1 \mathrm{D} \gamma-\mathrm{AlOOH}$ [26], $11.4 \pm 0.2$ for 2D $\gamma$-AlOOH [26], and $10.5 \pm 0.3$ for $2 \mathrm{D} \beta-\mathrm{FeOOH} / 2 \mathrm{D} \gamma$-AlOOH (see Figure $3(\mathrm{a})$ ). Those values are three $\mathrm{pH}$ units higher as compare to the average values for flat crystalline $\gamma-\mathrm{AlOOH}[26,27]$ and $\beta$-FeOOH [27] surfaces. Borghi et al. [28] observed a remarkable reduction by several $\mathrm{pH}$ units of the isoelectric point (IEP) on rough nanostructured surfaces, with respect to flat crystalline rutile $\mathrm{TiO}_{2}$. In order to explain the observed behavior of IEP, Borghi et al. [28] considered the roughness-induced self-overlap of the electrical double layers as a potential source of deviation from the trend expected for flat surfaces. Contrary to the acidic behavior of nanostructured surfaces crystalline rutile (Lewis acid sites), siliceous particles coated with quantum size 2D, 1D $\gamma$-AlOOH and
$2 \mathrm{D} \beta-\mathrm{FeOOH}$ crystallites behave preferentially as basic loci [1].

In general, the total charge per unit surface area in the diffuse layer around a particle can be evaluated with the use of the Graham equation (see Eq. (6).3.27 of Ref. [17]). For a symmetric electrolyte $\left(z_{+}=-z_{-}=z\right)$ in water at $25^{\circ} \mathrm{C}$, the Graham equation is reduced to (see equation (6).3.28 of Ref. [17]):

$$
\sigma_{\mathrm{d}}=-11.74 c^{1 / 2} \sinh \left(19.46 z \psi_{\mathrm{d}}\right)
$$

where $\sigma_{\mathrm{d}}$ is in $\mu \mathrm{C} / \mathrm{cm}^{2}$ and $\psi_{\mathrm{d}}$ measures the electrostatic potential at, or very near to, the beginning of the diffuse double layer (i.e., $\psi_{\mathrm{d}} \approx \zeta$ ) in volts and $c$ is the ionic concentration in $\mathrm{mol} / \mathrm{L}$.

In the case of small potentials $(\zeta<100 \mathrm{mV}$ [29]) and a monovalent electrolyte $\left(z_{+}=-z_{-}=z=1\right)$, equation (4) can be approximated with good precision to equation (5):

$$
\begin{aligned}
\sigma_{\mathrm{d}} & \approx-230 \zeta c^{1 / 2} \text { for electrolyte with } z_{+} \\
& =-z_{-}=z=1 \text { and } \zeta<100 \mathrm{mV}
\end{aligned}
$$

This equation allows to estimate the charge density, $\sigma_{\mathrm{d}}$, at the beginning of the diffuse double layer as a function of $\mathrm{pH}$. A satisfactory model (e.g., a triple layer model (see Figure 6.10 .3 of Ref. [17]) of the interface should reproduce both the $\sigma_{0} / \mathrm{pH}$, where $\sigma_{0}$ is the surface charge density on the particle, and $\zeta / \mathrm{pH}$ curves as seen in Figure 3(b)).

Three morphological planes of different chemical composition exist at siliceous particles coated with $2 \mathrm{D}$ and $1 \mathrm{D}$ $\gamma$-AlOOH crystallites: $\gamma$-AlOOH face and edge layers, and siliceous basal layer which are complex oxides of the two constituents $\gamma$ - $\mathrm{AlOOH}$ and $\mathrm{SiO}_{2}$. Following a model proposed by Stumm for kaolinite [30], we can distinguish the following type of surface ligands at the silica and boehmite face and edge surfaces: $i$ ) $=\mathrm{MOH}$ groups such as $\mathrm{Al}-\mathrm{OH}-\mathrm{Al}$ groups at the boehmite face surface, $\mathrm{Si}-\mathrm{O}-\mathrm{Si}$ groups at the siliceous basal surface, and $=\mathrm{AlOH}$ and/or $=\mathrm{SiOH}$ groups at the boehmite edge surface; $i$ i) $\mathrm{XO}^{-}$group such as (Al-O-Si) where $\mathrm{Al}$ is situated at the boehmite edge surface and $\mathrm{Si}$ is on the siliceous basal surface (Figure 2(a)). Based on electron microscopic studies of a negative gold sol attachment to a kaolinite edge surface performed by Thiessen [31], van Olphen has shown a $\mathrm{pH}$-dependent charge at the edges of the kaolinite platelets (see Figure 22 of Ref. [32]). The conclusion was that the double-layer structure is challenging due to the fact that two crystallographically different surfaces are carrying a different type of double layers that under certain condition can have opposite signs. Measurements of the electric double layer (EDL) properties of $\mathrm{CaF}_{2}$ [33], $\alpha-\mathrm{Al}_{2} \mathrm{O}_{3}$ (Sapphire) [34], and $\mathrm{TiO}_{2}$ (Rutile) [35] indicated significant differences (up to $2 \mathrm{pH}$ units) between the isoelectric points in various crystallographic orientations of surfaces.

The $\mathrm{pH}_{\mathrm{PZC}}$ is the same as the isoelectric point (IEP) if there is no specific adsorption of other ions than the potential determining $\mathrm{H}^{+} / \mathrm{OH}^{-}$at the surface. At this point, the portion of the charge due to $\mathrm{H}^{+}$and $\mathrm{OH}^{-}$or their complexes becomes zero. At $\mathrm{pH} 11.4$, the $\mathrm{pH}_{\mathrm{PZC}}$ and the proton density, 
TABLE 1: Initial removal efficacy of biological particles as a function of $\mathrm{pH}$ and electrolyte ionic strength.

\begin{tabular}{|c|c|c|c|c|c|c|}
\hline Material & $\begin{array}{l}\text { Zeta potential, } \\
\mathrm{mV}\end{array}$ & $\mathrm{pH}$ & $\begin{array}{c}\text { Electrolyte ionic } \\
\text { strength, } \mathrm{m} M\end{array}$ & $\begin{array}{c}\text { Debye length, } \\
\lambda_{\mathrm{D},}{ }^{\mathrm{a}} \mathrm{nm}\end{array}$ & $\begin{array}{l}\text { RT Removal } \\
\text { efficacy, LRV }\end{array}$ & $\begin{array}{l}\text { MS2 Removal } \\
\text { efficacy, LRV }\end{array}$ \\
\hline $1 \mathrm{D} \gamma$-AlOOH/microglass ${ }^{\mathrm{b}}$ & $47 \pm 9$ & \multirow{5}{*}{7.0} & \multirow{3}{*}{$0.002(1)$} & \multirow{3}{*}{215} & $>7.0$ & 5.1 \\
\hline $2 \mathrm{D} \gamma-\mathrm{AlOOH} / \mathrm{DE}^{\mathrm{c}}$ & $56 \pm 9$ & & & & $>7.0$ & 6.3 \\
\hline $2 \mathrm{D} \beta-\mathrm{FeOOH} / 2 \mathrm{D} \gamma-\mathrm{AlOOH} / \mathrm{DE}^{\mathrm{d}}$ & $20 \pm 3$ & & & & $>7.0$ & $>6.0$ \\
\hline $1 \mathrm{D} \gamma-\mathrm{AlOOH} /$ microglass $^{\mathrm{b}}$ & $47 \pm 9$ & & \multirow{2}{*}{3400} & \multirow{2}{*}{0.16} & $7.7^{\mathrm{f}}$ & $3.8^{\mathrm{f}}$ \\
\hline $2 \mathrm{D} \gamma-\mathrm{AlOOH} / \mathrm{DE}^{\mathrm{c}}$ & $56 \pm 9$ & & & & $>7.1$ & 5.3 \\
\hline $1 \mathrm{D} \gamma-\mathrm{AlOOH} /$ microglass $^{\mathrm{b}}$ & $23 \pm 6$ & \multirow{4}{*}{10.5} & \multirow{2}{*}{$0.33(3)^{\mathrm{e}}$} & \multirow{2}{*}{17} & $>6.9^{\mathrm{f}}$ & $7.4^{\mathrm{f}}$ \\
\hline $2 \mathrm{D} \gamma-\mathrm{AlOOH} / \mathrm{DE}^{\mathrm{c}}$ & $15 \pm 3$ & & & & $>4.5$ & 3.1 \\
\hline $1 \mathrm{D} \gamma$-AlOOH/microglass ${ }^{\mathrm{b}}$ & $23 \pm 6$ & & \multirow{2}{*}{3400} & \multirow{2}{*}{0.16} & $7.7^{\mathrm{f}}$ & $3.8^{\mathrm{f}}$ \\
\hline $2 \mathrm{D} \gamma-\mathrm{AlOOH} / \mathrm{DE}^{\mathrm{c}}$ & $15 \pm 3$ & & & & 5.5 & 4.0 \\
\hline
\end{tabular}

Notes: a) For $\mathrm{NaCl}$ electrolyte with bulk concentration $c_{\mathrm{NaCl}}$ at $\mathrm{T}=25^{\circ} \mathrm{C}$ the Debye length equals to $\lambda_{D} \cong 0.304 / \sqrt{c_{\mathrm{NaCl}}}$ (in nm) where $c_{\mathrm{NaCl}}$ is the concentration of the salt, in mol/ $\mathrm{dm}^{3}$; b) Non-woven $1 \mathrm{D} \gamma$-AlOOH/microglass media; c) 3-mm $2 \mathrm{D} \gamma$-AlOOH/DE precoat [37]; d) 3-mm $2 \mathrm{D} \beta$-FeOOH/2D $\gamma$-AlOOH/DE precoat [37]; e) Logarithm reduction value; f) Removal efficacy by 2 layers of $1 \mathrm{D} \gamma$-AlOOH/microglass non-woven media.

$\Gamma_{\mathrm{H}}$, on $2 \mathrm{D} \gamma$-AlOOH face surface are zero (Figure $3(\mathrm{~b})$ ). In the present work, we assumed that the boehmite edge surface is protonated at the same level in the $\mathrm{pH}$ range from 3.0 to 10.5 (broken horizontal line in Figure 3(b)) and the protonation is proportional to the zeta potential at $\mathrm{pH} 10.5$ and is equal to the surface charge, $\Gamma_{\mathrm{H}}=\sigma^{\text {edge, }} \mathrm{pH}=10.5$. The surface charge of the edge surface in the $\mathrm{pH}$ range from 10.5 to 11.4 was estimated as:

$$
\sigma_{o}^{\text {edge, } 10.5<\mathrm{pH}<11.4}=\sigma_{o}^{\text {edge, } \mathrm{pH}=10.5}\left(\zeta^{\text {edge, } 10.5<\mathrm{pH}<11.4} / \zeta^{\mathrm{pH}=10.5}\right)
$$

The excess proton density $\Gamma_{\mathrm{H}}$, which is equal to the surface charge, $\sigma_{0}$, at the surface hydroxyl group is displayed as a function of $\mathrm{pH}$. Surface protonation of the $2 \mathrm{D} \gamma-\mathrm{AlOOH}$ crystallites is interpreted as a successive protonation of the two distinct types of $\mathrm{OH}$ group localized on boehmite face and edge surfaces. Under this assumption, we estimated the $\mathrm{pH}_{\mathrm{PZC}}$ values of the edge surface at approximately 11.4 \pm 0.2 and boehmite face surface at approximately $9.5 \pm 0.5$. The latter value is within accuracy with an average value of $8.7 \pm 0.9$ obtained for smooth boehmite surfaces [26, 27] and the former value is within accuracy with the $\mathrm{pH}_{\mathrm{PZC}}$ of aluminum hydroxide $\gamma$-AlOOH adjuvant of 11.4 [36] that is morphologically and geometrically similar to the nanofibers seen in Figure 1(a).

3.3. Removal Efficacy of Submicron Particles as a Function of $\mathrm{pH}$ and Electrolyte Ionic Strength. Table 1 shows initial removal efficacy of biological particles from aqueous solution associated with pressure-driven flow through micrometer size pores of either $2 \mathrm{D} \gamma$-AlOOH/DE or $2 \mathrm{D} \beta-\mathrm{FeOOH} / 2 \mathrm{D} \gamma$ $\mathrm{AlOOH} / \mathrm{DE}$ particles packed into a $3-\mathrm{mm}$ deep precoat [37] or through a $1 \mathrm{D} \gamma-\mathrm{AlOOH} / \mathrm{microglass}$ non-woven filter media $[6,7]$.

Table 1 displays that siliceous particles coated with $2 \mathrm{D}$ and $1 \mathrm{D} \gamma$-AlOOH and $2 \mathrm{D} \beta-\mathrm{FeOOH} / 2 \mathrm{D} \gamma-\mathrm{AlOOH} / \mathrm{DE}$ structures resulted in a high removal efficacy (in all cases greater than $99.9 \%$ ) of biological particles regardless of zeta potential value in the range from $15 \mathrm{mV}$ to $56 \mathrm{mV}$. Estimations show that Brownian displacement does not play significant role in removal efficacy of micron size Raoultella Terrigena (RT) bacteria in a $3 \mathrm{~mm}$ deep 2D $\gamma$-AlOOH/DE and 2D $\beta$ $\mathrm{FeOOH} / 2 \mathrm{D} \gamma$-AlOOH/DE precoats with mean flow pore size of $d_{\text {mean-flow }}=24 \pm 4 \mu \mathrm{m}$ for diatomaceous earth (DE) with average particle size of $80 \mu \mathrm{m}$ [2]. When the Stokes-Einstein equation [38] is applied to a spherical particle suspended in water, it produces an estimated root-mean-square displacement during a contact time of $4.5 \mathrm{~s}$ in a $3-\mathrm{mm}$ deep precoat of only $1.8 \mu \mathrm{m}$ in the case of RT bacteria. Furthermore, the electrostatic attraction should not play significant role in the case of RT bacteria due to highly efficient shielding by the electric double layer (EDL) layer with Debye length as short as $1.6 \AA$ in the $3.4 \mathrm{M} \mathrm{NaCl}$ electrolyte (Table 1 ). Anisotropic characteristics of EDL layer have been observed in numerous material systems (see, e.g., Refs. [34-30]). For instance, in recent study of dendrimer-biomembrane interaction [29], the self-assembly processes of a mixture of charged polyamidoamine (PAMAM) dendrimers and dipalmitoylphosphatidylcholine (DPPC) lipids were investigated by means of zeta potential analysis, Raman and X-ray scattering. Zwitterionic DPPC liposomes showed substantially different behaviors during their interaction with negatively charged sodium carboxylate terminated $\left(\mathrm{COO}^{-} \mathrm{Na}^{+}\right)$dendrimers or positively charged amino terminated $\left(-\mathrm{NH}_{2}\right)$ dendrimers [29].

3.4. Removal Efficacy of Bio Particles by a Mixture of Opposively Charged Particles. In this section, we will discuss the $3 \mathrm{D}$ flow structure associated with pressure-driven flow through micrometer size pores of a mixture of equal but opposite charged particles packed into a 3-mm deep precoat [37]. The surfaces of diatomaceous earth (DE) and 2D $\gamma$-AlOOH/ DE particles have similar but opposite values of zeta potentials [1]. In such a case, there is an excess of positive ions over the DE surface, but negative ions dominate over the 2D $\gamma$-AlOOH/DE surface to balance out the positive surface charge. The difference in the surface potential results in an electrostatic potential gradient within the local electric double layer (EDL) fields near the transition zone between the two regions. The presence of this potential gradient results 


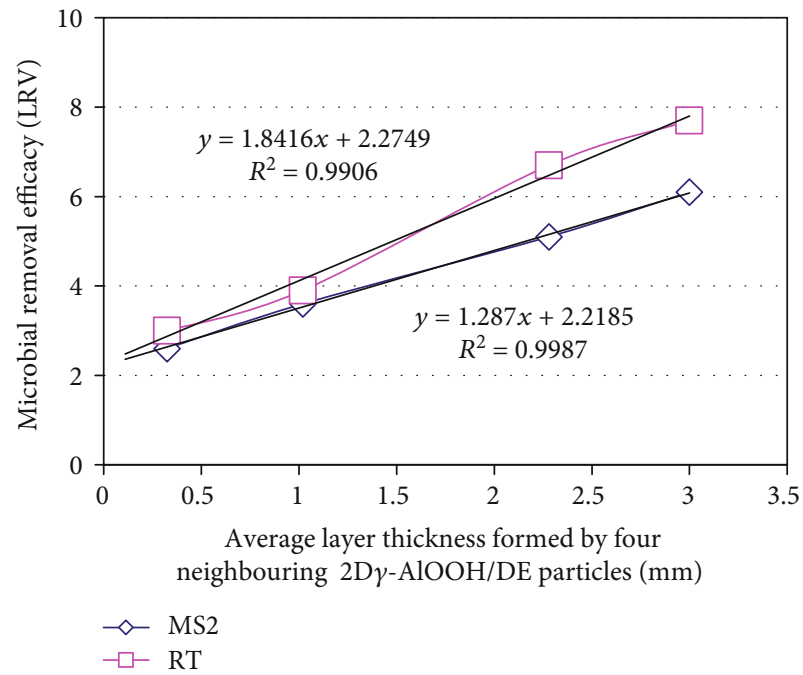

(a)

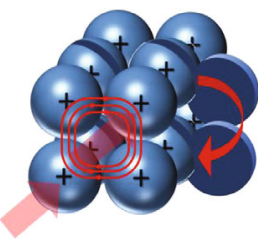

(b)

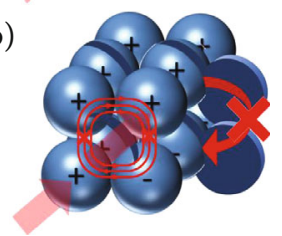

FIGURE 4: Removal efficacy of MS2 virus and RT bacteria by 3-mm deep precoat made from a mixture of 2D $\gamma$-AlOOH/DE and DE particles with equal average particle size [1,37]; $(\mathrm{a}, \mathrm{b})$ Diagram showing net surface charge density and velocity vector contours in the double layer region for the close cubic cell packing of: (a) 2D $\gamma$-AlOOH/DE particles; (b) Mixture of DE and 2D $\gamma$-AlOOH/DE particles.

TABLE 2: Removal efficacy of MS2 virus and RT bacteria by a mixture of equal size but opposively charged $2 \mathrm{D} \gamma$-AlOOH/DE and DE particles ${ }^{\mathrm{a}}$.

\begin{tabular}{|c|c|c|c|c|}
\hline $\begin{array}{l}\mathrm{Wt} \% \mathrm{DE} \text { in the mix of } \\
2 \mathrm{D} \gamma \text {-AlOOH/DE and } \mathrm{DE} \\
\text { particles in } 3 \mathrm{~mm} \text { precoat }\end{array}$ & $\begin{array}{l}\text { Average number of layers } \\
\text { formed by four neighboring } \\
2 \mathrm{D} \gamma \text {-AlOOH/DE particles }\end{array}$ & $\begin{array}{c}\text { Average layer thickness } \\
\text { formed by four neighboring } \\
2 \mathrm{D} \gamma \text {-AlOOH/DE particles, }{ }^{\mathrm{b}} \mathrm{mm}\end{array}$ & $\begin{array}{l}\text { MS2 removal } \\
\text { efficacy, LRV }\end{array}$ & $\begin{array}{l}\text { RT removal } \\
\text { efficacy, LRV }\end{array}$ \\
\hline 0 & 38 & 3.0 & $6.1 \pm 0.1$ & $>7.7$ \\
\hline 10 & 29 & 2.3 & $5.1 \pm 0.2$ & $6.7 \pm 0.5$ \\
\hline 25 & 13 & 1.0 & $3.6 \pm 0.4$ & $3.9 \pm 0.3$ \\
\hline 50 & 5 & 0.4 & $2.6 \pm 0.9$ & $3.0 \pm 0.3$ \\
\hline 75 & 1 & 0.1 & $1.0 \pm 0.2$ & $2.2 \pm 0.1$ \\
\hline 100 & 0 & 0.0 & $0.5 \pm 0.1$ & $0.7 \pm 0.2$ \\
\hline
\end{tabular}

Notes: a) Based on data of Ref. [1]; b) Proportional to the average number of layers formed by four neighboring 2D $\gamma$-AlOOH/DE particles (column 2).

in a body force on the microbes and/or ions in the double layer; however, in this case, an opposite body force is applied to the negative ions over the positively charged particle. As a result, the net body force over the region is zero and the circulation velocity perpendicular to the main flow becomes negligible [18-21]. For the purpose of this study, it was selected that 2D $\gamma$-AlOOH/DE and DE particles have equal average size of $d=80 \pm 3 \mu \mathrm{m}$. It was assumed to be packed in simple cubic cell with particles only at the corners as seen in Figure 4(a), 4(b). DE particles were mixed with 2D $\gamma$ $\mathrm{AlOOH} / \mathrm{DE}$ particles with DE content in the mix of 10-, 25-, 50-, and 75-wt\% and formed a 3-mm deep precoats $\left(\Delta_{\text {thickness }}=3 \mathrm{~mm}\right)$. Assuming a cubic cell packing, the number of layers is estimated as $N_{\text {layers }}=\Delta_{\text {thickness }} / d_{\text {average }} \sim 38$.

Table 2 shows removal efficacy of MS2 virus and Raoultella Terrigena (RT) bacteria by $3 \mathrm{~mm}$ precoats of diatomaceous earth (DE) particles coated with 2D $\gamma$-AlOOH crystallites mixed with uncoated DE particles at a flow velocity of $0.67 \mathrm{~mm} / \mathrm{s}$, neutral $\mathrm{pH} 7$ and ionic strength of $2 \pm 1 \mu \mathrm{M}$ [1]. The mean flow pore diameter of the precoat layer was determined to be $24 \pm 4 \mu \mathrm{m}$ [2]. Table 2 also provides experimental evidence of a behavior when a $3 \mathrm{~mm}$ precoat is losing adsorption properties of the 2D $\gamma$-AlOOH/DE at much faster rate than one can expect based on the weight fraction of $\mathrm{DE}$ in the mix. For example, for a 50/50-wt\% mix, one can expect a reduction in adsorption efficacy by a factor of two or by $\log _{10}(1 / 2)=-0.3$ based on the $2 \mathrm{D} \gamma-\mathrm{AlOOH} / \mathrm{DE}$ fraction in the mix while experimental reductions are $3.5 \pm 1.0$ logarithm reduction value (LRV) for MS2 virus and greater than 4.7 LRV for RT bacteria (Table 2). This is consistent with the case when at least one of the neighboring particles on the side of the cube perpendicular to the flow direction has opposite sign of the surface charge, i.e., $-\left|\sigma_{2}\right|$ for DE than the other neighboring particles, i.e., $+\left|\sigma_{1}\right|$ for $2 \mathrm{D} \gamma$-AlOOH/DE ceasing the circulation pattern in that pore involving four neighboring particles. That is, one DE particle is cancelling out high removal efficacy of three $2 \mathrm{D} \gamma$-AlOOH/DE particles situated on the same side of the cube perpendicular to the flow direction (Figure 4(b)).

The average number of layers in a pore formed by a group of four 2D $\gamma$-AlOOH/DE particles with no diatomaceous earth (DE) particle in the group decreases rapidly as DE loadings in the mix increases. Finally, Table 2 presents average number of layers in a pore of the precoat layer 
TABLE 3: Initial removal efficacy of bioparticles at neutral $\mathrm{pH}$ as a function of ageing ${ }^{\mathrm{a}}$.

\begin{tabular}{|c|c|c|c|}
\hline Material & Ageing time & RT removal efficacy, ${ }^{a}$ LRV & MS2 removal efficacy, ${ }^{\mathrm{a}}$ LRV \\
\hline \multirow{2}{*}{$1 \mathrm{D} \gamma-\mathrm{AlOOH} /$ microglass $^{\mathrm{b}}$} & As produced & $>6.5$ & $>7.0$ \\
\hline & Aged for 14 years & $>7.0$ & $>7.3$ \\
\hline \multirow{2}{*}{$2 \mathrm{D} \gamma-\mathrm{AlOOH} / \mathrm{DE}^{\mathrm{c}}$} & As produced & $>7.3$ & $>7.0$ \\
\hline & Aged for 7 years & $>7.3$ & $>6.2$ \\
\hline \multirow{2}{*}{$2 \mathrm{D} \beta-\mathrm{FeOOH} / 2 \mathrm{D} \gamma-\mathrm{AlOOH} / \mathrm{DE}^{\mathrm{d}}$} & As produced & $>6.8$ & $>5.8$ \\
\hline & Aged for 7 years & $>7.3$ & $>5.4$ \\
\hline
\end{tabular}

Notes: a) Based on data of Ref. [1]; b) Non-woven media; c) DE with average particle size of $18 \mu \mathrm{m}$; d) DE with average particle size of $60 \mu \mathrm{m}$.

formed by a group of four 2D $\gamma$-AlOOH/DE particles with no DE particle in the group together with the average layer thickness in the 3-mm precoat formed by four neighboring $2 \mathrm{D} \gamma$-AlOOH/DE particles with no DE particle in the group.

\subsection{Removal Efficacy of Bioparticles due to Particle} Interactions. Another important reason why siliceous particles coated with $2 \mathrm{D}$ and $1 \mathrm{D} \gamma-\mathrm{AlOOH}$ and $2 \mathrm{D} \beta-\mathrm{FeOOH} / 2 \mathrm{D} \gamma$ $\mathrm{AlOOH} / \mathrm{DE}$ structures resulted in a high removal efficacy of biological particles is their strong electropositive charge properties when dispersed in polar liquids. These media's structure assemblies create a strong field that extends from the alumina surface into an aqueous dispersive medium, which is many orders $(>4)$ greater than the one predicted by the DerjaguinLandau-Verwey-Overbeek (DLVO) theory, especially at high ionic strength [12]. It is important to note that the DLVO theory was developed for smooth, homogeneous particles with ideal geometries and with no EDL overlap $[9,10]$. For this reason, the stronger field extension observed in the media can be simply explained by the general impact of roughness, which is to amplify the long-range behaviour of noncontact DLVO forces with the amplification factor of exponential force between rough and smooth surfaces [12]. The adsorption mechanism is mainly influenced by the combination of their inherent charge and the acquired induced polarization charge, rather than by physical entrapment based on particle size. 2D and $1 \mathrm{D} \gamma$-AlOOH and 2D $\beta-\mathrm{FeOOH} / 2 \mathrm{D} \gamma \mathrm{AlOOH} / \mathrm{DE}$ structures have a high dynamic response for adsorption, allowing purification within very shallow bed at high flow velocities and low differential pressure $[1,2]$.

3.6. Flow Mixing via Electrokinetic Circulation. Electrokinetic phenomena are typically second-order phenomena, e.g., in streaming current measurements, an applied mechanical force produces an electric current [14]. When treated phenomenologically, the second order phenomena can be treated by irreversible thermodynamics [15]. Even though classical thermodynamics describes electric double layer (EDL) at rest, in electrokinetics EDL is not at rest. However, usually the deviations from the equilibrium distribution of charge are disregarded [15].

Figure 4 shows removal efficacy of MS2 virus and Raoultella Terrigena (RT) bacteria by $3-\mathrm{mm}$ deep precoat of $2 \mathrm{D} \gamma-\mathrm{AlOOH} / \mathrm{DE}$ and diatomaceous earth (DE) particle mixture with equal average particle sizes of $80 \mu \mathrm{m}$ as a function of average layer thickness formed by four neighboring 2D $\gamma$-AlOOH/DE particles.
Figure 4 also reveals good correlation (coefficient of determination $\mathrm{R}^{2}>0.99$ ) between logarithm reduction values (LRV) of microbial removal efficacy and average layer thickness formed by four neighboring 2D $\gamma$-AlOOH/DE particles (Table 2):

$$
\log _{10}\left(C_{\text {initial }} / C_{\text {filtrate }}\right)=x / x_{0}+a,
$$

where $a$ is a constant and $x_{0}$ is the average thickness of 2D $\gamma$-AlOOH/DE layer within a mix that would reduce the initial concentration, $C_{\text {initial }}$, by a factor of 10 . The thickness of $2 \mathrm{D} \gamma-\mathrm{AlOOH} / \mathrm{DE}$ precoat layer that would reduce concentration of biological particles in the water stream by a factor of 10 is equal to $x_{0}$ (MS2) $=0.8 \mathrm{~mm}$ for MS2 virus and $x_{0}(\mathrm{RT})=0.5 \mathrm{~mm}$ for RT bacteria.

3.7. Ageing Characteristics of the $2 \mathrm{D}$ and $1 \mathrm{D} \gamma$-AlOOH Crystallites. The main application of the prepared $2 \mathrm{D} \gamma$ $\mathrm{AlOOH}, 1 \mathrm{D} \gamma-\mathrm{AlOOH}$, and $2 \mathrm{D} \beta-\mathrm{FeOOH} / 2 \mathrm{D} \gamma-\mathrm{AlOOH}$ crystallites deposited on diatomaceous earth (DE) particles is as water purification media. Additionally, since we are proposing a low cost and large-scale production of these crystallites, it was important to know their stability throughout the time. For this reason, the removal efficacy of aqueous particles by the prepared $1 \mathrm{D}, 2 \mathrm{D} \gamma-\mathrm{AlOOH}$, and $2 \mathrm{D} \beta-\mathrm{FeOOH} / 2 \mathrm{D} \gamma$ $\mathrm{AlOOH}$ crystallites was evaluated after fourteen and seven years, respectively (Table 3 ).

From the results presented in Table 3 , it was found that the prepared $1 \mathrm{D}, 2 \mathrm{D} \gamma-\mathrm{AlOOH}$ and $2 \mathrm{D} \beta-\mathrm{FeOOH} / 2 \mathrm{D} \gamma$ $\mathrm{AlOOH}$ crystallites remain monocrystalline under ambient conditions and no degradation in performance (i.e., TEM, particle size distribution, etc.) was noticed over periods of seven to fourteen years of manufacturing. This finding makes the crystallites to be industrially applicable.

\section{Conclusions}

In conclusion, aluminum-water reaction (equation (1)) has successfully been used to produce 2D and 1D quantumsized and nanometer-sized $\gamma$-AlOOH mesostructures deposited onto siliceous substrates in a one-step process at moderate temperature [6-8]. Low cost, large scale manufacturing (several metric tons per year) of siliceous substrates coated with $2 \mathrm{D}$ and $1 \mathrm{D}$ arrays of $\gamma$-AlOOH crystallites and further functionalized with $2 \mathrm{D}$ atomically thin nanobelts of akaganeite $\beta$-FeOOH crystallites was demonstrated. A model explaining the $\mathrm{pH}$ dependent behavior of the zeta 
potential based on contributions from the three morphological planes of different chemical composition existing at siliceous particles coated with $2 \mathrm{D}$ and $1 \mathrm{D} \gamma$-AlOOH crystallites was proposed: $\gamma$-AlOOH face and edge layers, and siliceous basal layer which are complex oxides of the two constituents: $\gamma$-AlOOH and $\mathrm{SiO}_{2}$. The isoelectric point values of rough 2D $\gamma$-AlOOH, $1 \mathrm{D} \gamma-\mathrm{AlOOH}$, and 2D $\beta$-FeOOH/2D $\gamma$-AlOOH crystallites deposited on DE surfaces were increased by three $\mathrm{pH}$ units as compare to the flat crystalline $\gamma$-AlOOH and $\beta$-FeOOH surfaces resulting in a high removal efficacy of submicron particles from aqueous suspension by the surfaces with combined microscale and nanoscale structures. This suggests the existence of coupling electrokinetic effect of the local electric double layer (EDL) fields with the local flow fields which was further confirmed by a good correlation (coefficient of determination $\mathrm{R}^{2}>0.99$ ) between LRV values of microbial removal efficacy and average layer thickness formed by four neighboring $2 \mathrm{D} \gamma$-AlOOH/DE particles (Table 2). Finally, the prepared 2D and 1D $\gamma$-AlOOH crystallites remain monocrystalline under ambient conditions and no degradation in characteristics (i.e., TEM, particle size distribution, etc.) and performance (i.e., virus, bacteria and metal ion removal efficacy) was noticed over periods of several years (i.e., seven to fourteen years).

\section{Data Availability}

The data used to support the findings of this study are included within the article.

\section{Conflicts of Interest}

No potential conflict of interest was reported by the authors.

\section{References}

[1] L. Kaledin, F. Tepper, Y. Vesga, and T. Kaledin, “The effect of the surface roughness and ageing characteristics of boehmite on the removal of biological particles from aqueous solution," AIMS Materials Science, vol. 6, no. 4, pp. 498-508, 2019.

[2] L. Kaledin, F. Tepper, and T. Kaledin, "Electrokinetic aspects of water filtration by $\mathrm{AlOOH}$-coated siliceous particles with nanoscale roughness," AIMS Materials Science, vol. 4, no. 2, pp. 470-486, 2017.

[3] S. Farrah and D. Preston, "Concentration of viruses from water by using cellulose filters modified by in situ precipitation of ferric and aluminum hydroxides," Applied and Environmental Microbiology, vol. 50, no. 6, pp. 1502-1504, 1985.

[4] J. Lukasik, S. Farrah, S. Truesdail, and D. Shah, "Adsorption of microorganisms to sand diatomaceous earth particles coated with metallic hydroxides," Kona Powder and Particle Journal, vol. 14, pp. 87-91, 1997.

[5] S. E. Truesdail, J. Lukasik, S. R. Farrah, D. O. Shah, and R. B. Dickinson, "Analysis of bacterial deposition on metal (hydr)oxide-coated sand filter media," Journal of Colloid and Interface Science, vol. 203, no. 2, pp. 369-378, 1998.

[6] F. Tepper and L. Kaledin, "Nanosize electropositive fibrous adsorbent," in U.S Patent No. 6,838,005, U.S. Patent and Trademark Office, Washington, DC, 2005.
[7] F. Tepper and L. Kaledin, "Drinking water filtration device," in US Patent No. 7,390,343, U.S. Patent and Trademark Office, Washington, DC, 2008.

[8] L. Kaledin, F. Tepper, and T. Kaledin, "Aluminized silicious powder and water purification device incorporating the same," in US Patent No. 9,309,131, U.S. Patent and Trademark Office, Washington, DC, 2016.

[9] B. Derjaguin and L. Landau, "Theory of the stability of strongly charged lyophobic sols and of the adhesion of strongly charged particles in solutions of electrolytes," Progress in Surface Science, vol. 43, no. 1-4, pp. 30-59, 1993.

[10] E. Verwey and J. Overbeek, Theory of the Stability of Lyophobic Colloids, Elsevier, Amsterdam, 1948.

[11] C. Schnitzer and S. Ripperger, "Influence of surface roughness on streaming potential method," Chemical Engineering and Technology, vol. 31, no. 11, pp. 1696-1700, 2008.

[12] D. Parsons, R. Walsh, and V. Craig, "Surface forces: surface roughness in theory and experiment," The Journal of Chemical Physics, vol. 140, no. 16, p. 164701, 2014.

[13] S. Seeger, B. Palm, J. Günster, and J. Heinrich, "On the influence of the particle size on the zeta potential of ultra-pure silica powders," Ber DKG, vol. 92, no. 4, pp. E35-E40, 2015.

[14] J. Lyklema, Fundamentals of Interface and Colloid Science: Solid-Liquid Interfaces, vol. 2, Academic Press, San Diego, 1995, Chaps.

[15] J. Lyklema, Fundamentals of Interface and Colloid Science: Fundamentals, vol. 1, Academic Press, London, 1991.

[16] J. Lyklema, "Electrokinetics after Smoluchowski," Colloids and Surfaces A: Physicochemical Engineering Aspects, vol. 222, no. 1-3, pp. 5-14, 2003.

[17] R. Hunter, Foundations of Colloid Science, Chapt. 6, 8, Oxford University Press, Oxford, 2001.

[18] R. C. Cohen and C. J. Radke, "Streaming potentials of nonuniformly charged surfaces," Journal of Colloid and Interface Science, vol. 141, no. 2, pp. 338-347, 1991.

[19] D. Li, Electrokinetics in microfluidics, in Interface science and technology, Ed. A, vol. 2, no. 6, 2004, Habbard, Elsevier, Amsterdam, 2004, Chap.

[20] D. Erickson and D. Li, "Microchannel flow with patchwise and periodic surface heterogeneity," Langmuir, vol. 18, no. 23, pp. 8949-8959, 2002.

[21] D. Erickson and D. Li, "Streaming potential and streaming current methods for characterizing heterogeneous solid surfaces," Journal of Colloid and Interface Science, vol. 237, no. 2, pp. 283-289, 2001.

[22] W. H. Gitzen, Alumina as a Ceramic Material, American Ceramic Society, Special Publication 4, Westerville, The American Ceramic Society, Ohio, 1970.

[23] A. K. Geim and I. V. Grigorieva, "Van der Waals heterostructures," Nature, vol. 499, no. 7459, pp. 419-425, 2013.

[24] X. Bokhimi, J. Toledo-Antonio, M. Guzman-Castillo, and F. Hernandez-Beltran, "Relationship between crystallite size and bond lengths in boehmite," Journal of Solid State Chemistry, vol. 159, no. 1, pp. 32-40, 2001.

[25] R. P. Nair, P. Blake, A. N. Grigorenko et al., "Fine structure constant defines visual transparency of graphene," Science, vol. 320, no. 5881, p. 1308, 2008.

[26] L. Kaledin, F. Tepper, and T. Kaledin, "Pristine point of zero charge (p.p.z.c.) and zeta potentials of boehmite's nanolayer and nanofiber surfaces," International Journal of Smart and Nano Materials, vol. 7, no. 1, pp. 1-21, 2016. 
[27] M. Kosmulski, Surface Charging and Point of Zero Charge, CRC Press, Taylor \& Francis group, Boca Raton, 2009.

[28] F. Borghi, V. Vyas, A. Podesta, and P. Milani, "Nanoscale roughness and morphology affect the isoelectric point of titania surfaces," PLoS One, vol. 8, no. 7, article e68655, 2013.

[29] D. Lombardo, P. Calandra, E. Bellocco et al., "Effect of anionic and cationic polyamidoamine (PAMAM) dendrimers on a model lipid membrane," Biochimica et Biophysica Acta (BBA) - Biomembranes, vol. 1858, no. 11, pp. 2769-2777, 2016.

[30] W. Stumm, Chemistry of the Solid-Water Interface: Processes at the Mineral Water and Particle-Water Interface in Natural Systems, Wiley-Interscience, New York, 1992.

[31] P. A. Thiessen, "Kennzeichnung submikroskopischer Grenzflächenbereiche verschiedenartiger Wirksamkeit," Zeitschrift für Anorganische Chemie, vol. 253, no. 3-4, pp. 161-169, 1947.

[32] H. van Olphen, An Introduction to Clay Colloid Chemistry, John Wiley and Sons, New York, 2nd Ed. edition, 1977.

[33] S. Assemi, J. Nalaskowski, J. Miller, and W. Johnson, "Isoelectric point of fluorite by direct force measurements using atomic force microscopy," Langmuir, vol. 22, no. 4, pp. 1403-1405, 2006.

[34] R. Kershner, J. Bullard, and M. Cima, "Zeta potential orientation dependence of sapphire substrates," Langmuir, vol. 20, no. 10, pp. 4101-4108, 2004.

[35] J. Bullard and M. Cima, "Orientation dependence of the isoelectric point of $\mathrm{TiO}_{2}$ (rutile) surfaces," The Journal of Physical Chemistry, vol. 99, pp. 2114-2118, 1995.

[36] H. Hogenesch, "Mechanism of Immunopotentiation and safety of aluminum adjuvants," Frontiers in Immunology, vol. 3, article 406, 2013.

[37] Argonide Corporation, Preparation of 3- $\mathrm{mm}$ deep precoat from $80 \mu \mathrm{m}$ DE powders, 2015, http://www.tinyurl.com/my6jmzz.

[38] A. Einstein, Investigations on the Theory of the Brownian Movement, Dover Publications, New York, NY, 1956. 


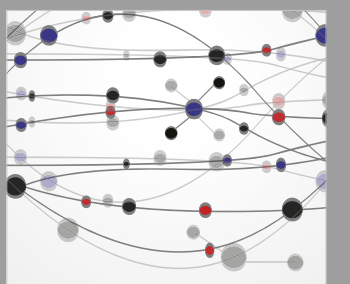

The Scientific World Journal
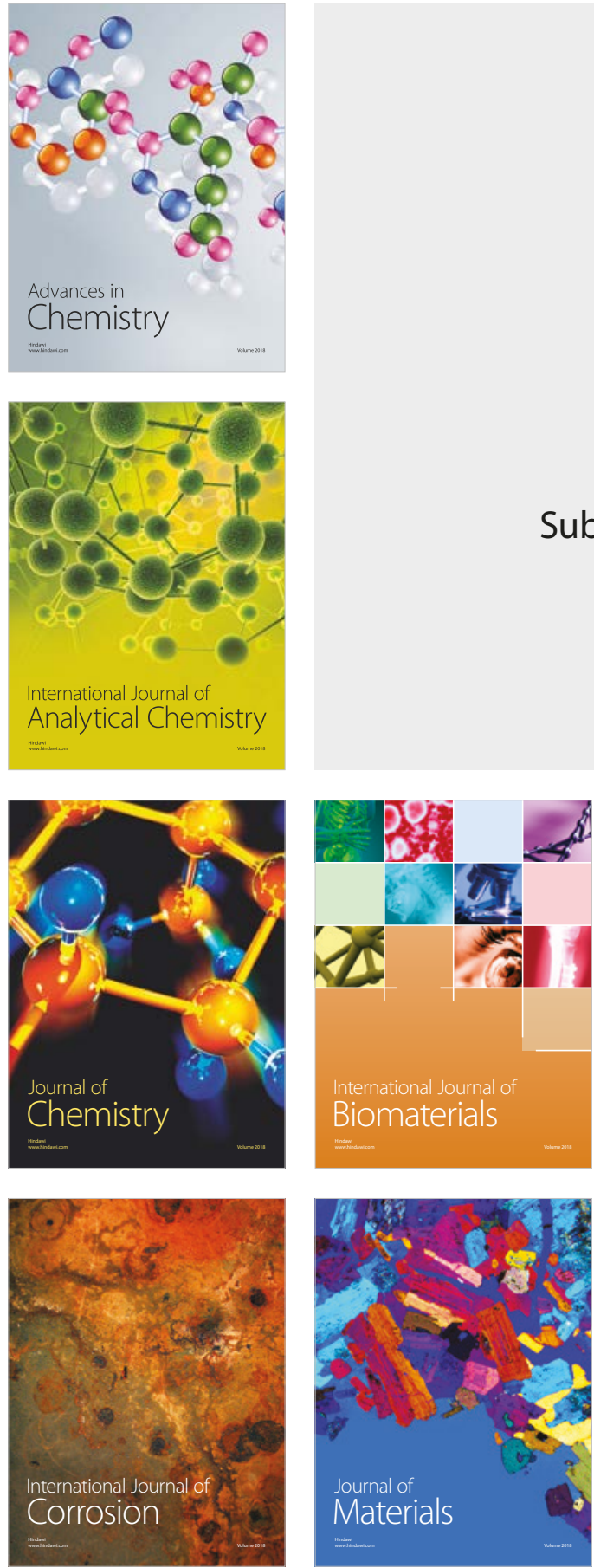

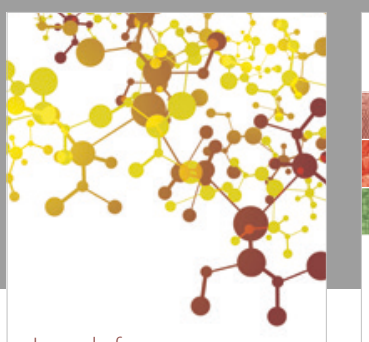

Journal of

Applied Chemistry
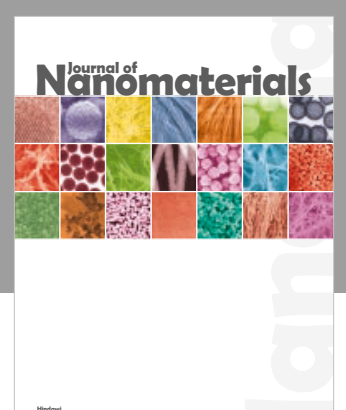

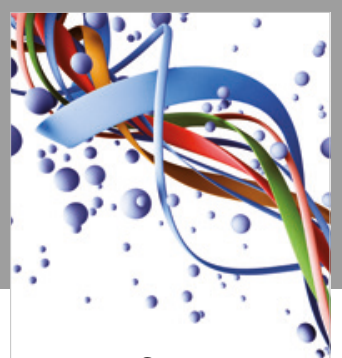

Scientifica

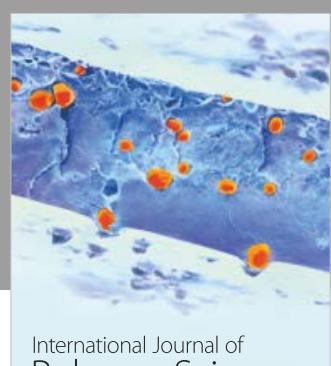

Polymer Science

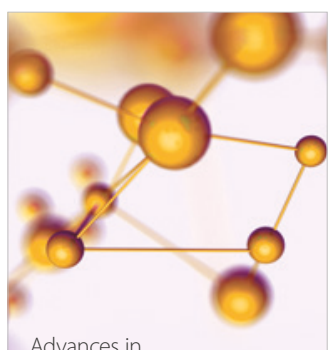

Physical Chemistry
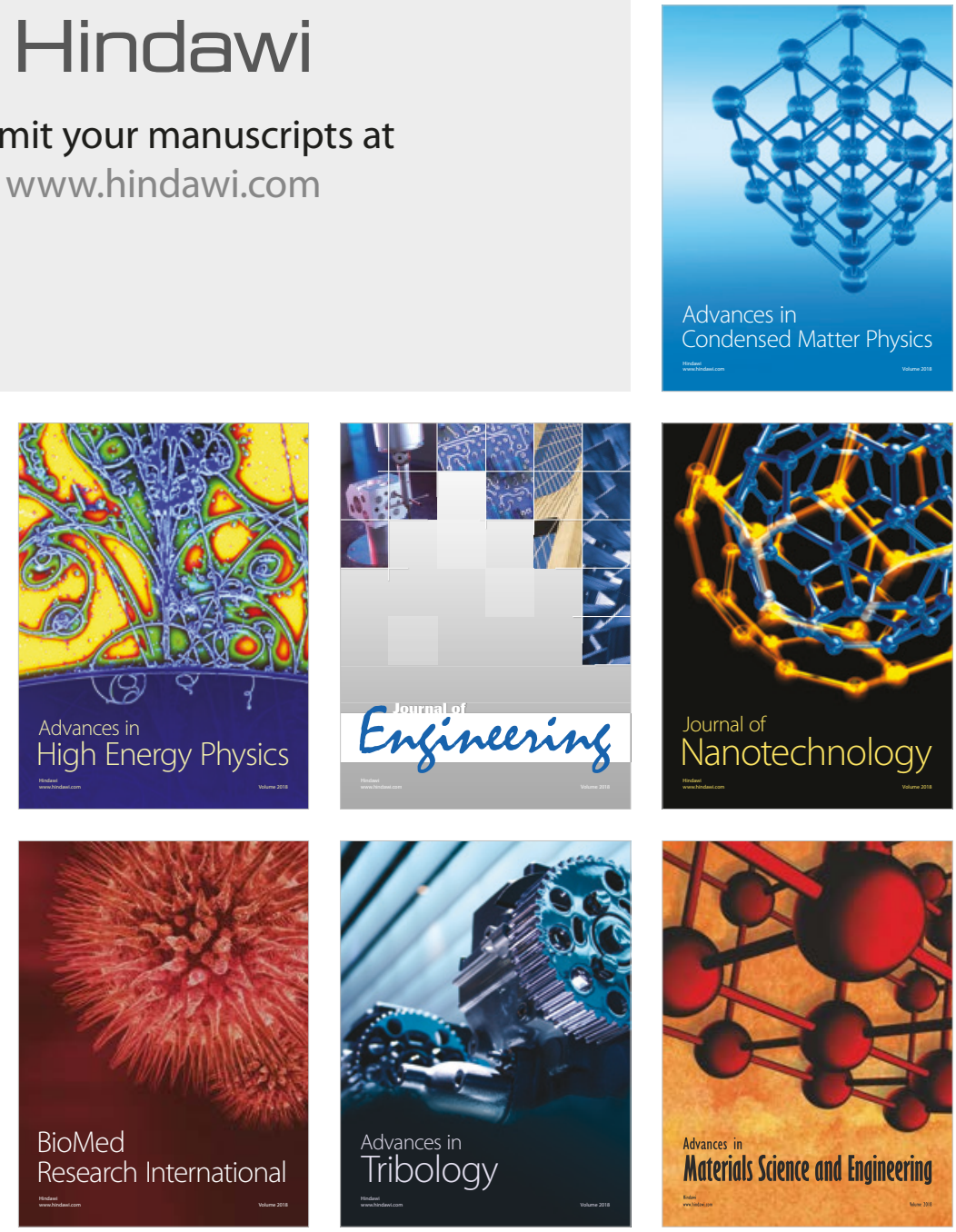